\title{
PERANCANGAN SMART - TV MENGGUNAKAN PERINTAH SUARA DENGAN METODE HIDDEN MARKOV MODEL
}

Adi Kurniawan Saputro

Program Studi Teknik Elektro,

Fakultas Teknik

Universitas Trunojoyo Madura,

Bangkalan, Indonesia adi.kurniawan@trunojoyo. ac.id

\author{
Miftachul Ulum \\ Program Studi Teknik \\ Elektro, \\ Fakultas Teknik \\ Universitas Trunojoyo \\ Madura, \\ Bangkalan, Indonesia \\ miftachul.ulum@trunojoyo \\ .ac.id
}

\author{
Anton Karim \\ Program Studi Teknik \\ Elektro, \\ Fakultas Teknik \\ Universitas Trunojoyo \\ Madura, \\ Bangkalan, Indonesia \\ ak3299718@gmail.com
}

\author{
Riza Alfita., ST., MT. \\ Program Studi Teknik \\ Elektro, \\ Fakultas Teknik \\ Universitas Trunojoyo \\ Madura, \\ Bangkalan, Indonesia \\ yogya_001@yahoo.com
}

\begin{abstract}
Salah satu teknologi yang sedang berkembang saat ini adalah perintah suara yang mengolah suara menjadi suatu perintah agar dapat dikenal oleh alat elektronik. Penelitian ini menggambarkan pengenalan pola suara untuk mengontrol, menghidupkan, mematikan dan mengganti channel televisi secara otomatis sebagai pengganti remote. Alat ini bertujan untuk memberikan inovasi dalam pengembangan dunia teknologi yang dititik beratkan pada pengenalan perintah suara. Metode yang digunakan adalah Hidden Markov Model untuk mengeksekusi fungsi perangkat melalui perintah suara . Sinyal suara dicuplik sehingga menjadi sinyal digital kemudian dinormalisasi dan diproses dengan preprocessing signal menggunakan metode LPC (Linear Predective Coding) selanjutnya dianalisis dan dicari nilai probabilitas yang maksimum sehingga dapat dikenali menggunakan Hidden Markov Model (HMM). Dengan konsep tersebut maka smart-tv dapat dikendalikan dengan perintah suara dari penggunannya.
\end{abstract}

Kata kunci : Voice Command, Televisi, HMM, LPC

\section{PENDAHULUAN}

Perkembangan teknologi saat ini sangat pesat. Kita dapat melakukan banyak hal dengan teknologi, salah satunya adalah saat kita menggunakan remot untuk mengontrol suatu benda. Kita dapat menjumpai berbagai alat tersebut pada beberapa peralatan rumah tangga hingga alat kerja kantor. Alat tersebut berguna untuk mempermudah pekerjaan manusia. Sebagai salah satu contoh pemanfaatan perintah suara sebagai alat pengontrol televisi. Sistem kontrol dengan menggunakan suara menjadi salah satu alternatif yang mudah dan efektif terutama untuk para pengguna yang memiliki keterbatasan fisik. Namun penerapan sistem kontrol menggunakan suara tidak mudah dilakukan oleh mesin. Diperlukan suatu metode pembelajaran pada mesin untuk dapat mengekstraksi dan mengenali ciri atau pola suara dengan mempelajari ciri-ciri sebelumnya.

Perintah suara adalah sutau teknologi yang dapat mengolah suara menjadi suatu perintah yang dapat dikenal oleh suatu mesin elektronik. Dengan munculnya teknologi ini memungkinkan seseorang memberikan perintah pada mesin elektronika dengan menggunakan suara yang masuk melalui microfon[1]. Dengan menerapkan teknologi Pengenalan perintah suara, sistem ini dapat menghidupkan dan mematikan peralatan rumah tangga dengan bantuan dari mikrokontroler Arduino uno. Diharapkan dengan dikembangkannya sistem tersebut akan memudahkan manusia yang memiliki keterbatasan dalam fisik maupun dapat meningkatkan kenyamanan dalam kehidupan sehari-hari.

Terdapat beberapa metode untuk mengekstrak ciri sinyal suara diantaranya LPC (Linear Predective Coding). LPC mencuplik sinyal suara sehingga menjadi sinyal digital, kemudian dinormalisasi dan diproses dengan preprocessing signal dan HMM (Hidden Markov Model) [2] untuk mengeksekusi perintah suara. ISSN 2615-5788 Print (2615-7764)

C2020 JURNAL TEKNIK ELEKTRO DAN KOMPUTER TRIAC

Vol. 7 No. 2 Tahun 2020
Metode ini telah diaplikasikan pada beberapa bidang diantaranya, game teka-teki silang, kontrol aplikasi winamp, deteksi emosi, deteksi kelainan jantung, kontrol lampu dan kipas angin.

\section{BAHASA DAN METODE}

\section{A. Implemetasi}

Dalam metode eksprimen pengujian sistem terbagi menjadi beberapa bagian percobaan di antaranya pengujian terhadap sensor IR(Infrared), bluetooth, dan pengujian program mikrokontroler.

\section{B. Hidden Markov Model (HMM)}

HMM merupakan model statistik yang menggambarkan urutan peristiwa. HMM memiliki keuntungan bahwa dinamika temporal fitur Prasetio, dkk, Pengenalan Emosi Berdasarkan Suara ucapan dapat terdeteksi oleh Matrik state transisi. Selama clustering, sinyal ucapan diambil dan probabilitas untuk setiap sinyal suara dihitung. Output klasifikasi didasarkan pada probabilitas maksimum yang dimiliki model yang telah dihasilkan sinyal tersebut [3].

Dalam perancangan, sistem ini mampu mendetesi dan mengklasifikasikan berdasarkan suara yang diterima. Sistem pengenalan suara untuk mengenali chanel TV apa yang akan diproses dan dilakukan pergantian. Secara umum, teknik pengenalan suara dapat dilihat pada Gambar 1 .

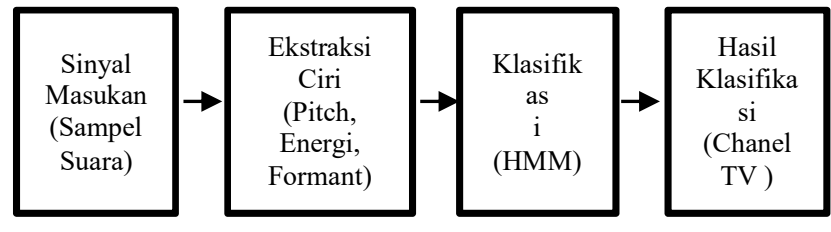

Gambar 1. Teknik Pengenalan Suara

\section{Linear Predective Coding (LPC)}

Ekstrasi penegenalan suara adalh merubah glombang suara menjadi beberapa tipe. Salah satu caranya dengan menggunakan metode LPC diturunkan dari ide dasar bahwa contoh sinyal ucapan pada saat ke $n, s(n)$, dapat didekati sebagai kombinasi linier dari sejumlah p contoh ucapan sebelumnya[4], sebagai berikut :

$$
\begin{aligned}
& \hat{S}_{n} \approx a_{1} s(n-1)+a_{2} s(n-2)+\cdots+a_{i} s(n-i) \\
& \hat{S}_{n}=\sum_{i=1}^{p} a_{i} s_{n-i}
\end{aligned}
$$

Langkah-langkah analisis LPC untuk mendapatkan koefisien LPC pada proses ekstraksi ciri suara adalah sebagai berikut [5]: 
1. Preemphasis

2. Frame blocking

3. Windowing

4. Analisis autokorelasi

5. Analisis LPC

6. Konversi parameter LPC

7. Pembobotan Parameter

8. Turunan Temporal Koefisien Cepstral

Pada setiap frame dari sinyal setelah melalui proses windowing, kemudian dilakukan analisis autokorelasi dan dilakukan tahap Analisa hingga turunan temporal koefisien cepstral. Analisa proses autokorelasi sebagai berikut:

$$
r_{1}(m)=\sum_{n=0}^{N-1-m} \breve{X}_{1}(n) \breve{X}_{1}(n+m), m=0,1, \ldots, p . .
$$

\section{Bluetooth $\mathrm{HC}-05$}

Bluetooth HC-05 merupakan module komunikasi nirkabel pada frekuensi $2.4 \mathrm{Ghz}$ dengan pilihan koneksi dapat sebagai slave ataupun master. Sangat mudah digunakan dengan mikrokontroller untuk membuat aplikasi wireless.Interface yang digunakan adalah serial RXD, TXD, VCC dan GND. Built in LED sebagai indikator koneksi bluetooth. Tegangan input bluetooth versi ini $3.6-6 \mathrm{~V}$, jangan menghubungkan dengan sumber daya lebih dari $7 \mathrm{~V}$. Arus saat unpaired sekitar $30 \mathrm{~mA}$ dan saat paired sebesar $10 \mathrm{~mA}$. 4 pin $3.3 \mathrm{~V}$ dapat langsung dihubungkan ke berbagai macam mikrokotroller (khusus Arduino, 8051, 8535, AVR, PIC, ARM, MSP430, etc.). Jarak efektif jangkauan sebesar 10 meter, meskipun dapat mencapai lebih dari 10 meter, namun kualitas koneksi makin berkurang.[6]

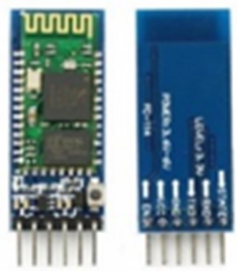

Gambar 2. Modul Bluetooth HC-05

\section{E. Mikrokontroler Arduino uno}

Mikrokontroler adalah sistem mikroprosesor lengkap yang terkandung di dalam sebuah chip. Mikrokontroler berbeda dari mikroprosesor serba guna yang digunakan dalam sebuah PC (Personal Computer), karena sebuah mikrokontroler umumnya telah berisi komponen pendukung sistem minimal mikroprosesor, yakni memori dan antarmuka I/O.[7]

Pada perancangan alat ini terdapat beberapa tahapan agar perencanaan sesuai dengan yang diharapkan. Berikut rancangan sistem dalam bentuk blok diagram.

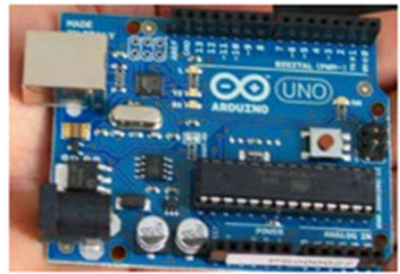

Gambar 3. Mikrokontroler Arduino uno
Pada perancangan alat ini terdapat beberapa tahapan agar perencanaan sesuai dengan yang diharapkan. Berikut rancangan sistem dalam bentuk blok diagram.

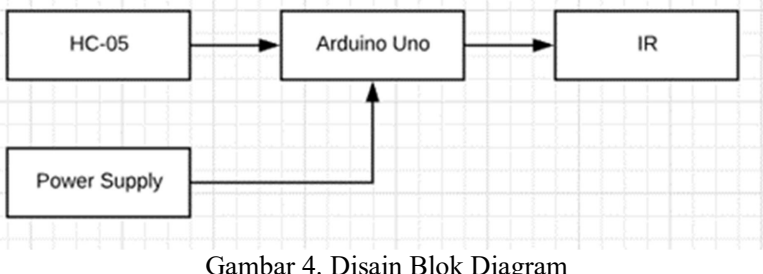

Pada blok diagram gambar 4 perangkat keras terdapat input berupa HC-05 bluetooth dan output berupa IR. HC-05 menerima sinyal berupa character dari android yang kemudian diproses pada Arduino Uno. arduino tersebut akan mencocokkan character yang dikirim oleh Smartphone tersebut. Hasilnya akan dikirim pada TV melalui IR berupa kode remote pada TV tersebut.

\section{Alur Diagram Alat}

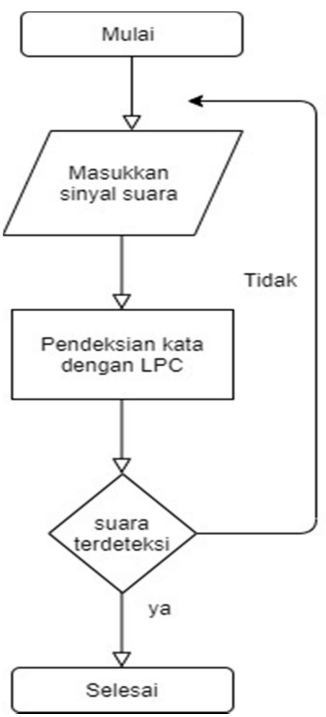

Gambar 5. Flowchart Sistem

Pada gambar 5 flowchat smart tv dijelaskan bahwa awal mula adalah proses penerimaan data pada buetooth yang akan diproses dan dibandingkan dengan pengiriman suara dengan metode LPC. Metode tersebut digunakan untuk ekstraksi ciri pada pengiriman data pada TV. Jika suara terdeteksi maka pengiriman tersebut akan dilanjutkan dengan mengirimkan pada TV melalui IR.

\section{Konsep Sistem}

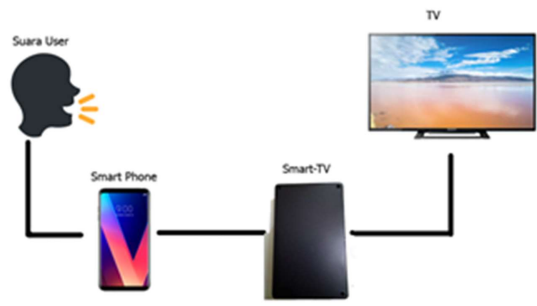

Gambar 6. Konsep Sistem 
Pada gambar 6 dijelaskan pada konsep sistem tersebut terdapat suara pengguna Smartphone, sart-TV dan TV. Pada konsep tersebut dimulai dari sura pengguna yang menyebutkan kata-kata tentang channel TV seperti SCTV, Indosiar, GlobalTV dll. Suara tersebut akan diambil oleh smartphone yang sudah terdapat aplikasi smart$T V$. Aplikasi tersebut akan mengirimkan kode pada Smart-TV sehingga Smart-TV dapat mengganti channel atau setting pada TV secara otomatis[8]. Dengan mengolah suara menjadi suatu perintah yang dapat dikenal oleh suatu mesin sehingga memungkinkan seseorang melakukan remote pada aplikasi yang ada pada computer.

\section{Perancangan Sistem}

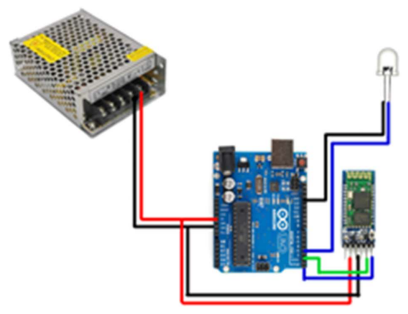

Gambar 7. Perancangan Sistem

Pada perancangan sistem ini terdapat arduino uno, power supply, Bluetooth, dan IR. Pada arudino pin yang digunakan adalah pin Rx dan Tx untuk menghubungkan Bluetooth. Kemudian pin 3 digunakan untuk menghubungkan IR. Untuk Vinput menggunakan power supply $12 \mathrm{~V}$ [9] untuk mensupply arduino Uno. Pada modul buletooth $\mathrm{HC} 05$ terdapat 4 pin dimana pin tersebut dilengkapi dengan VCC, GND, TX dan RX. Pin tersebut dihubungkan pada arduino uno sehingga buetooth dapat digunakan sebagai mana fungsinya. Untuk modul IR menggunakan pin 3 karena umumnya pin 3 digunakan untuk mengontrol IR.

\section{HASIL DAN PEMBAHASAN}

Sistem kerja alat ini sangat sederhana dan mudah dalam penggunaan sehari-hari. Kita hanya melakukan perintah suara pada smartphone kita. Selanjutnya smartphone akan mengirim data dengan merubah sinyal suara menjadi digital dengan format hexa ke bluetooth alat yang telah kita buat dan di proses oleh arduino untuk memindahkan cahanel tv sesuai dengan yang kita inginkan.

\section{A. Pengujian Sistem}

Pada pengujian ini bekerja sesuai ketentuan yang di berikan atau sukses. Pengujian dilakun sebanyak 30 kali secara acak.

TABEL 1. HASIL PENGUJIAN KOMUNIKASI BLUETOOTH HC-05

\begin{tabular}{|c|c|c|c|}
\hline No & $\begin{array}{c}\text { Pengiriman } \\
\text { Android }\end{array}$ & $\begin{array}{c}\text { Penerimaan } \\
\text { Bluetooth }\end{array}$ & Jumlah kesalahan \\
\hline 1 & A & A & 3 \\
\hline 2 & B & B & 2 \\
\hline 3 & C & C & 2 \\
\hline 4 & D & D & 4 \\
\hline 5 & E & E & 5 \\
\hline 6 & F & F & 4 \\
\hline 7 & G & G & 4 \\
\hline 8 & H & H & 3 \\
\hline 9 & I & I & 4 \\
\hline 10 & J & J & $88.3 \%$ \\
\hline \multicolumn{3}{|c|}{ Rata-rata keberhasilan } & \\
\hline
\end{tabular}

Tabel II. Hasil pengujian PembacaAn Chanel

\begin{tabular}{|c|c|c|c|}
\hline No & IR Kirim & Channel TV & $\begin{array}{c}\text { Jumlah } \\
\text { kesalahan }\end{array}$ \\
\hline 1 & $0 \times 910$ & SCTV & 3 \\
\hline 2 & $0 \times 10$ & Indosiar & 5 \\
\hline 3 & $0 \times 810$ & Global tv & 3 \\
\hline 4 & $0 \times 410$ & Rcti & 4 \\
\hline 5 & $0 \times 10$ & ANTV & 4 \\
\hline 6 & $0 \times 490$ & Besar Volume & 3 \\
\hline 7 & $0 \times 90$ & Kecil Volume & 4 \\
\hline 8 & 0xA10 & Power & 3 \\
\hline \multicolumn{3}{|c|}{ Rata-rata keberhasilan } & $87.9 \%$ \\
\hline
\end{tabular}

\section{KESIMPULAN}

Kesimpulan dari hasil penelitian dijelaskan pada bagian ini : 1.Perancangan SMART-TV dapat bekerja sesuai dengan metode HIDDEN MARKOV MODEL dengan presentase keberhasilan komunikasi Bluetooth $88.3 \%$ dan hasil pengujian Pembacaan Chanel TV 87.9\%.

2.Sistem komuniksi bekerja dengan baik, wireless bluetooth dan aplikasi android

3.Perlu dilakukan pengujian lebih pada metode LPC dengan kata yang lebih panjang.

\section{DAFTAR PUSTAKA}

[1] A. Purwarianti and H. B. Firdaud, "Implementasi Pendiktean Bahasa Indonesia," J. Ilmu Komput. dan Inf., vol. 4, no. 1, p. 51, 2011, doi: 10.21609/jiki.v4i1.152.

[2] R. Kusumawati, "Metode Linear Predictive Coding (LPC) Pada klasifikasi Hidden Markov Model (HMM) Untuk Kata Arabic pada penutur Indonesia," Matics, vol. 8, no. 1, p. 32, 2016, doi: 10.18860/mat.v8i1.3481.

[3] B. Schuller, G. Rigoll, and M. Lang, "Hidden Markov model-based speech emotion recognition," Proc. - IEEE Int. Conf. Multimed. Expo, vol. 1, pp. I401-I404, 2003, doi: 10.1109/ICME.2003.1220939.

[4] J. Sangeetha, S. Jothilakshmi, and R. N. Devendrakumar, "Efficient continuous speech recognition approaches for dravidian languages," Int. J. Simul. Syst. Sci. Technol., vol. 15, no. 2, pp. 14-23, 2014, doi: 10.5013/IJSSST.a.15.02.03.

[5] S. N. Rohman, A. Hidayanto, and A. A. Zahra, "Aplikasi Pencirian Dengan Linear Predictive Coding Untuk Pembelajaran Pengucapan Nama Hewan Dalam Bahasa Inggris Menggunakan Jaringan Syaraf Tiruan Propagasi Balik," Transmisi, vol. 14, no. 4, pp. 1-9, 2012.

[6] B. Sugiantoro, "Aplikasi Teknologi Bluetooth untuk Komunikasi Wireless," Semin. Nas. Apl. Teknol. Inf. 2005 (SNATI 2005), vol. 2005, no. Snati, pp. 1-7, 2010.

[7] P. Handoko, "Sistem Kendali Perangkat Elektronika Monolitik Berbasis Arduino Uno R3," no. November, pp. $1-2,2017$.

[8] M. S. Son, "Pengembangan Mikrokontroler Sebagai Remote Control Berbasis Android," J. Tek. Inform., vol. 11, no. 1, pp. 67-74, 2018, doi: 10.15408/jti.v11i1.6293.

[9] K. Semarang, "Optimalisasi Penggunaan Alat Praktikum Power Supply Switching dengan Menggunakan Topologi Half Bridge Konverter sebagai Alat Bantu Praktikum Elektronika Analog," Optim. Pengguna. Alat Prakt. Power Supply Switch. dengan Menggunakan Topol. Half Bridg. Konvert. sebagai Alat Bantu Prakt. Elektron. Analog, vol. 12, no. 1, pp. 1-8, 2018, doi: 10.14710/metana.v12i1.17509. 